\title{
Factsheet: The impact of the nationwide COVID-19 lockdown on adult New Zealanders' experiences of unwanted digital communications
}

\author{
Prepared by Neil Melhuish \& Dr. Edgar Pacheco
}

This factsheet presents findings from a study looking at the prevalence of unwanted digital communications in New Zealand during the nationwide COVID-19 lockdown.

In December 2019 an infectious coronavirus disease, commonly known as COVID-19, was identified in Wuhan, China. The disease spread rapidly and became a global pandemic with, at the time of writing, 57 million COVID-19 cases and 1.5 million related deaths being reported worldwide'.

New Zealand's first COVID-19 case was confirmed on 28 February 2020, after which the number of cases began to rise significantly, prompting the New Zealand Government to introduce a nationwide lockdown on 25 March 2020. New Zealand's response to the pandemic has so far resulted in one of the lowest rates per million of cases and deaths in the OECD (Bretschger et al., 2020). However, achieving and maintaining this level of impact on medical health from COVID-19 has required significant disruption in New Zealand's social and economic life (Anderson et al., 2020; Poulton et al., 2020), with evidence of the potential psychological consequences of the lockdown beginning to emerge (Every-Palmer et al., 2020; Sibley et al., 2020).

As New Zealand's lockdown got underway, the number of reports about harmful digital communications that Netsafe's call centre received began to increase, with this trend continuing beyond the lockdown period. Similar patterns were observed in the UK and Australia by organisations providing comparable support services (Lane \& Mottram, 2020; Medhora, 2020; SWGfL, 2020), suggesting the concurrence of increased reporting about online abuses and the imposition of lockdown might not be coincidental. However, this operational evidence is limited, and while some research about this phenomenon is beginning to emerge, evidence of the impact of the COVID-19 lockdown based on nationally representative data is absent.

To address this, Netsafe has undertaken a quantitative study with adult New Zealanders to explore how prevalent the experiences of unwanted digital communication were in the last 12 months, before, during, and just after the nationwide COVID 19 lockdown. The findings from this study provide a source of robust information for researchers and policy makers seeking to learn lessons from New Zealanders' online experiences during the pandemic.

1 See Johns Hopkins University of Medicine Coronavirus Resource Center: https://coronavirus.jhu.edu/map.html 
Between 2 June and 7 July 2020, we carried out a nationally representative survey that asked New Zealand adults about their personal experiences of receiving unwanted digital communications in the previous 12 months and, if they had, when this had occurred in relation to the nationwide lockdown. Unwanted digital communications include "a range of online experience(s) mediated/facilitated by unsolicited electronic communication(s) that might or might not cause distress and/or harm to the person who deals with it (e.g. receiving spam, accidentally seeing inappropriate content, having rumours spread about oneself, being threatened online)." (Pacheco \& Melhuish, 2018). See Methodology section for details.

\section{Highlights}

1. This study found a higher prevalence of unwanted digital communications around the time of the nationwide COVID-19 lockdown. Of those who reported receiving unwanted digital communications, 4 in 10 indicated that these experiences occurred in the last three months during and/or after lockdown, just prior to completing this survey.

2. Some types of unwanted digital communications were more likely than others to be sent during and/or after lockdown. These involved trying to get the person receiving it to hurt themselves or shared their intimate images or recordings without their permission.

3. There were demographic differences in the prevalence of unwanted digital communications received during and/or just after the lockdown. Males, 40-49-year-olds, adults with long-term disabilities and those identifying with non-heterosexual orientations were more likely to experience this, while Māori were least likely compared to other ethnicities.

4. This study has implications for policy, research, and practice in relation to preparedness for supporting people through such high-impact low-frequency events, including potential future iterations of COVID-19 lockdown. This study's findings suggest that unexpected health and social events, such as the COVID-19 pandemic and compulsory lockdown, are factors that can trigger changes in people's experiences of online risk from unwanted digital communications. 


\section{Findings}

\section{Prevalence of unwanted digital communications during, before, and/or after lockdown}

Around four in ten participants reported having received at least one unwanted digital communication in the past year. Of those participants ( $n=484), 41 \%$ experienced this during the 3 months during and/or just after lockdown, while 35\% reported it had occurred in the 9-month period before lockdown started.

$41 \%$ of adults that received at least one unwanted digital communication experienced this during and/or after lockdown, and 35\% before lockdown.

Percentage of participants receiving unwanted digital communications before, during and/or after lockdown
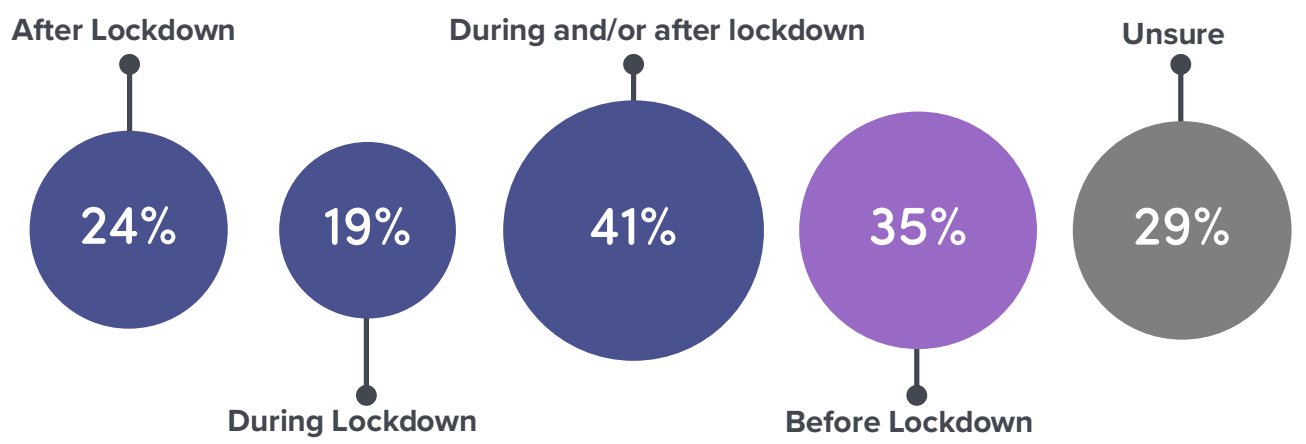

Base: Participants that received at least one unwanted digital communication in the last 12 months ( $n=484)$.

Note: Participants were allowed multiple responses.

\section{Experiences of different demographic groups}

Some demographic groups were more likely to receive at least one unwanted communication during or just after the lockdown period than before.

Regarding gender, of those that received at least one unwanted digital communication in the last year, males (46\%) were more likely than females (36\%) to say that this experience had taken place during and/or after the lockdown period.

Males that received unwanted digital communications in the last year were more likely to experience this during and/or after lockdown than females.

Percentage of participants receiving unwanted digital communications before, during and/or after lockdown, by gender

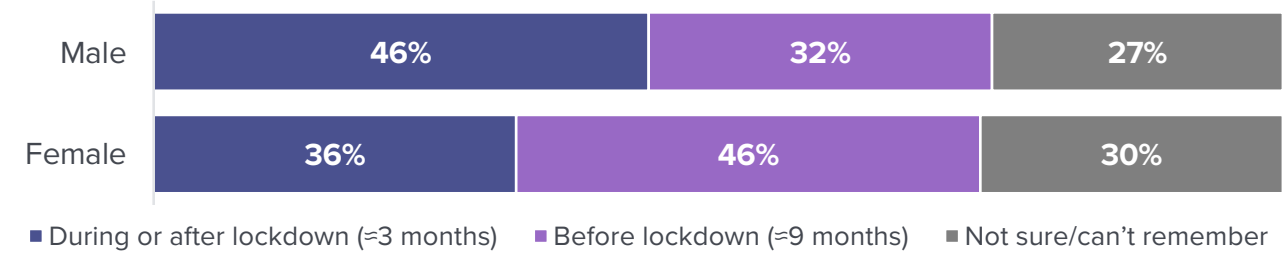

Base: Participants that received at least one unwanted digital communication in the last 12 months (n=484).

Note: Participants were allowed multiple responses. 
Regarding age, of the participants that received an unwanted digital communication in the last year, those in the 40-49 age group reported experiencing this during or in the weeks following the lockdown (56\%), followed by $18-29$-year-olds (47\%) and 30-39-year-olds (34\%). Participants who were 50 years and older were least likely to be sure or remember when they received unwanted digital communications relative to the lockdown.

40-49-year-olds that received at least one unwanted digital communication were more likely to experience this during and/or after lockdown than other age groups.

Percentage of participants receiving unwanted digital communications before, during and/or after lockdown, by age group

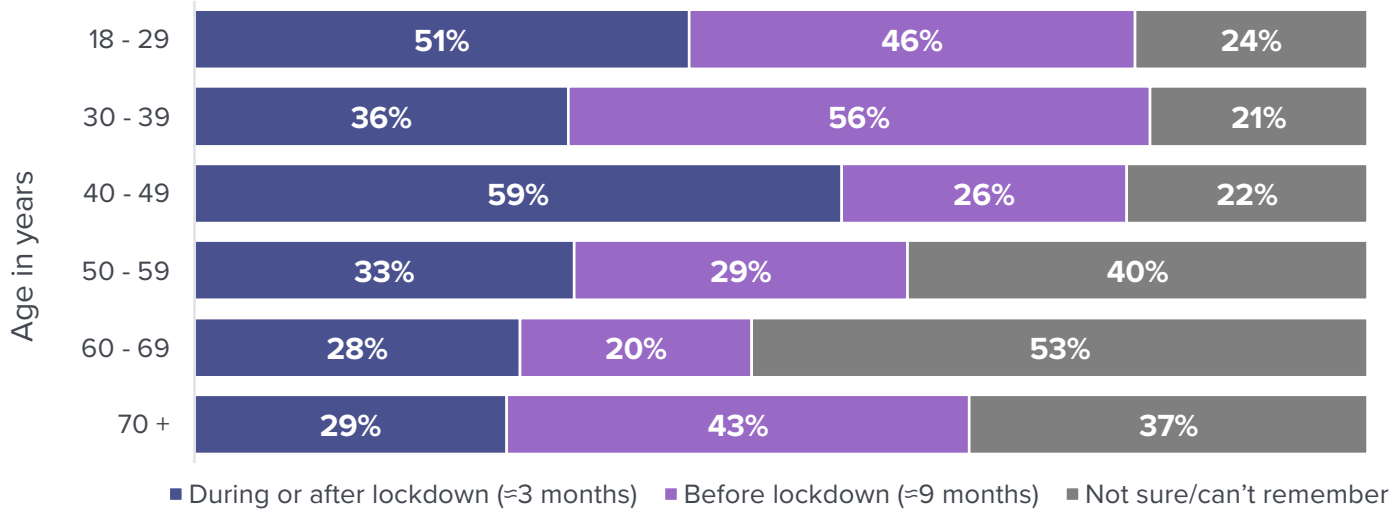

Base: Participants that received at least one unwanted digital communication in the last 12 months ( $n=484$ ).

Note: Participants were allowed multiple responses.

Regarding ethnicity, of those that received at least one unwanted digital communication in the last year, NZ European/ Pākehā participants were most likely while Māori participants were least likely to experience this during and/or after the lockdown period (44\% and $30 \%$ respectively).

Māori receiving at least one unwanted digital communication in the last year were less likely than other ethnicities to experience this during and/or after lockdown.

Percentage of participants receiving unwanted digital communications before, during and/or after lockdown, by ethnicity

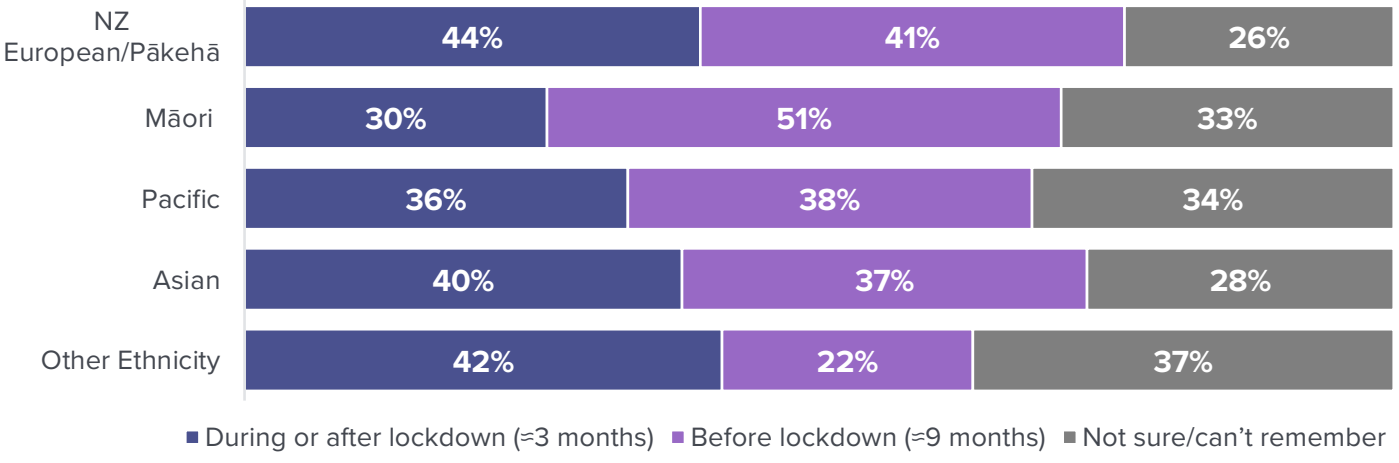

Base: Participants that received at least one unwanted digital communication in the last 12 months ( $n=484)$.

Note: Participants were allowed multiple responses. 
Participants living with long-term disabilities that received an unwanted digital communication were more likely to experience this during lockdown compared to those without disability.

\section{Around six in ten New Zealanders with long-term disabilities that received unwanted digital communications did so during and/or after the lockdown period. \\ Percentage of participants receiving unwanted digital communications before, during and/or after lockdown, by long-term disability

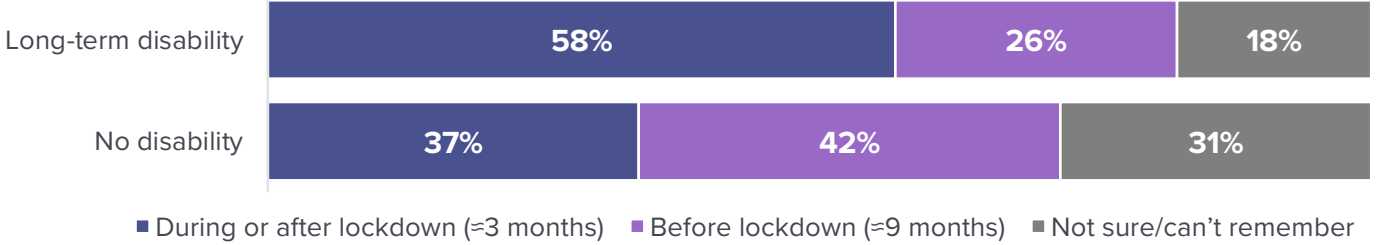

Base: Participants that received at least one unwanted digital communication in the last 12 months (n=484). Participants with long-term disabilities ( $n=321$ ) and without disability $(n=98)$.

Note: Participants were allowed multiple responses.

Further, participants identifying with gay, lesbian, bisexual or other sexual orientations (nonheterosexual) were by far more likely to have experienced unwanted digital communication during/after lockdown (61\%) than those identifying as heterosexual (38\%).

\section{Seven in ten adults identifying with non-heterosexual orientations that received unwanted digital communications experienced this during and/or after lockdown.}

Percentage of participants receiving unwanted digital communications before, during and/or after lockdown, by sexual identity

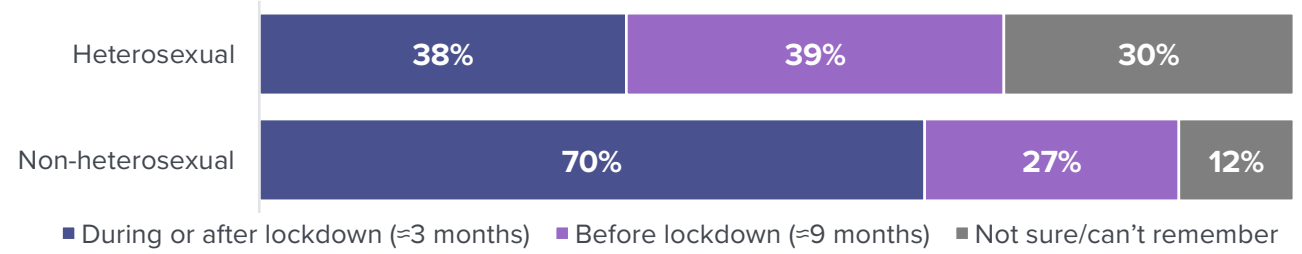

Base: Participants that received at least one unwanted digital communication in the last 12 months (n=484). Participants identifying with heterosexual ( $n=392)$ and non-heterosexual ( $n=39)$ orientations.

Note: Participants were allowed multiple responses.

\section{Occurrence of different types of unwanted digital communication}

New Zealanders that received at least one unwanted digital communication were more likely to receive some types more frequently than others during and/or immediately after lockdown. Some types of unwanted digital communication that were received in the last 12 months were more likely to have been experienced during or just after lockdown. The two most prevalent were communications that shared intimate images or recordings of the person without their permission $65 \%$ during and/or after lockdown) and those that tried to get the recipient to hurt themselves e.g., self-harm, or commit suicide (65\% during or after lockdown). Of the physically threatening or intimidating communications received in the last year, over one third (36\%) were sent during the 7-week lockdown. However in the period just after lockdown a disproportionate number of unwanted sexual advances were received (39\% of all received in the previous year), followed by communications that shared intimate images or recordings of the recipient without permission (37\%) and those that tried to get the recipient to hurt themselves (36\%). 
Around three in ten of all the participants that received an unwanted digital communication in the previous year were not sure or could not remember when they had experienced this in relation to the lockdown period. Interestingly, there was a greater level of certainty among participants about when some types of communication had been received, possibly because distinct or emotionally involving events are easier to recall than frequent or typical events (Lavrakas, 2008). These included communications that tried to get the recipient to hurt themselves directly ( $8 \%$ unsure or couldn't remember) or indirectly by encouraging someone else to try to harm them (10\%) and stalking to intimidate or control.

\section{Some types of unwanted digital communications were more likely to be sent in the three months during and/or after lockdown.}

Percentage of participants receiving unwanted digital communications before, during and/or after lockdown, by type

\begin{tabular}{|c|c|c|c|}
\hline Type of unwanted digital communication & $\begin{array}{l}\text { During and/or } \\
\text { after } \\
\text { lockdown }\end{array}$ & $\begin{array}{l}\text { Before } \\
\text { lockdown }\end{array}$ & $\begin{array}{l}\text { Not sure/ can't } \\
\text { remember }\end{array}$ \\
\hline Physically threatened or intimidated you & $53 \%$ & $32 \%$ & $21 \%$ \\
\hline Excluded you from a peer or friendship group & $48 \%$ & $37 \%$ & $22 \%$ \\
\hline $\begin{array}{l}\text { Tried to embarrass or humiliate you online in } \\
\text { front of your peers or friends }\end{array}$ & $45 \%$ & $46 \%$ & $18 \%$ \\
\hline $\begin{array}{l}\text { Said offensive things about you, your lifestyle or } \\
\text { your religious or political beliefs }\end{array}$ & $54 \%$ & $41 \%$ & $16 \%$ \\
\hline $\begin{array}{l}\text { Included violent or sexual content you thought } \\
\text { was indecent or obscene }\end{array}$ & $55 \%$ & $44 \%$ & $24 \%$ \\
\hline $\begin{array}{l}\text { Made a false allegation about your personal or } \\
\text { professional life }\end{array}$ & $43 \%$ & $51 \%$ & $15 \%$ \\
\hline $\begin{array}{l}\text { Was just one of many unwanted communications } \\
\text { received from the same person }\end{array}$ & $44 \%$ & $35 \%$ & $29 \%$ \\
\hline Made an unwanted sexual advance to you & $53 \%$ & $42 \%$ & $16 \%$ \\
\hline $\begin{array}{l}\text { Stalked you by monitoring your online activity to } \\
\text { intimidate or control you }\end{array}$ & $52 \%$ & $50 \%$ & $10 \%$ \\
\hline $\begin{array}{l}\text { Shared intimate images or recordings of you } \\
\text { without your permission }\end{array}$ & $65 \%$ & $34 \%$ & $15 \%$ \\
\hline $\begin{array}{l}\text { Came from people that had been encouraged by } \\
\text { someone else to try to harm you }\end{array}$ & $55 \%$ & $50 \%$ & $10 \%$ \\
\hline Tried to get you to hurt yourself & $65 \%$ & $45 \%$ & $8 \%$ \\
\hline Was harmful in another way & $54 \%$ & $49 \%$ & $11 \%$ \\
\hline
\end{tabular}




\section{About Netsafe research}

Netsafe carries out research as a wider part of its statutory role as approved agency under the Harmful Digital Communications Act 2015 to inform the design and delivery of its resources and services and provide research-based evidence for others working to address online safety issues. The topic of this report sits within the scope of the Act's ten communications principles that together describe a range of potentially harmful types of online communications ${ }^{2}$.

To contact Netsafe for more information about its research programme or how you can contribute contact: research@netsafe.org.nz

For more information about New Zealand's Harmful Digital Communications Act 2015 and Netsafe's Approved Agency role visit: https://www. netsafe.org.nz/hdc-act/

\section{What's next on this topic?}

Netsafe has also collected data about adult New Zealanders under lockdown in relation to other experiences of unwanted digital communication, for example online hate speech, that it will be publishing over the coming months.

\section{Acknowledgements}

We would like to thank Lisa Thornhill and Michael Dunne, Colmar Brunton's Social Research Agency, for their contribution to survey development and initial data analysis.

2 See Harmful Digital Communications Act 2015, s 6(1). 


\section{Methodology}

The data for this study was collected as part of Netsafe's 2020 Annual Population Survey, a large quantitative study that explores the interaction between adult New Zealanders and digital technologies in the context of the Harmful Digital Communications Act 2015. The Act's principles (s.6) informed the types of unwanted communications we asked about, specifically, whether they had:

- Physically threatened or intimidated them

- Excluded them from a peer or friendship group

- $\quad$ Tried to embarrass or humiliate them online

- Said offensive things about them, their lifestyle or religious or political beliefs

- Included violent or sexual content they thought was indecent or obscene

- Made a false allegation about their personal or professional life

- Were just one of many unwanted communications received from the same person

- Made an unwanted sexual advance to them (e.g. messages propositioning sex acts)

- Stalked them by monitoring their online activity to intimidate or control them

- Shared intimate images or recordings of them without their permission

- Came from people that had been encouraged by someone else to try to harm them

- Tried to get them to hurt themselves (e.g. self-harm, commit suicide)

- Was harmful in another way.

The survey was conducted between 2 June and 7 July 2020 by Colmar Brunton's Social Research team. Participants came from a representative sample $(n=1,150)$ of the population of New Zealand adults (aged 18+) in terms of age, gender, ethnicity, religion, and region. Overall results are weighted to the 2018 Census count. The maximum margin of error for the whole sample is $\pm 3.1 \%$ at the $95 \%$ confidence level. Data was also collected for people identifying with diverse genders, however the small sample size $(n=4)$ means it was not possible to draw statistically relevant conclusions for this group. Non-representative data was collected from participants identifying with gay, lesbian, bisexual or other sexual orientations; this was combined $(n=69)$ to enable statistically robust comparisons. Therefore, in this factsheet we refer to participants as identifying either as heterosexual or as nonheterosexual. Non-representative data was also collected for participants with long-term disabilities $(n=180)$. Note that the percentages presented in this factsheet may not total exactly $100 \%$ because participants were allowed to choose multiple answers or due to rounding.

In the survey we asked participants that said they received an unwanted digital communication in the previous year ( $n=484$ ) whether this had occurred in the last month (since lockdown ended), two to three months (during lockdown), four to six months (before lockdown started), and/or over 6 months ago and less than 12 months ago. Participants were told that 'lockdown' meant the 7-week period starting 26 March until 14 May 2020, when the Government asked New Zealanders to stay home to slow the spread of COVID-19 under alert levels 3 and $4^{3}$. Because of when the survey was in the field the 'after lockdown' time period varies from $=3$ to 7 weeks. Therefore, in this factsheet the 'during and/or after lockdown' period is approximated to 3 months and 'before lockdown' to 9 months.

While this study provides unique insight on adult New Zealanders' digital experiences during the COVID-19 lockdown period, it also has limitations. In particular, it is possible that questionnairerelated error is introduced by asking participants to recall past events. This is addressed, for example, by clearly stating time frames to avoid ambiguity and ease recall, using alert level changes as critical events to bound participants' recall, and providing an "unsure" option (Lavrakas, 2008).

\footnotetext{
3 For a summary of the New Zealand COVID-19 alert levels see: https://covid19.govt.nz/assets/resources/tables/COVID-19-alertlevels-summary.pdf
} 


\section{References}

Anderson, D., Dominick, C., Langley, E., Painuthara, K., \& Parker, S. (2020). Rapid Evidence Review: The immediate and medium-term social and psycho-social impacts of COVID-19 in New Zealand. https://www.msd.govt.nz/documents/about-msd-and-our-work/publicationsresources/statistics/covid-19/social-impacts-of-covid-19.pdf

Bretschger, L., Grieg, E., Welfens, P. J. J., \& Xiong, T. (2020). COVID-19 infections and fatalities developments: empirical evidence for OECD countries and newly industrialized economies. International Economics and Economic Policy. https://doi.org/10.1007/s10368-020-00487-x

Every-Palmer, S., Jenkins, M., Gendall, P., Hoek, J., Beaglehole, B., Bell, C., Williman, J., Rapsey, C., \& Stanley, J. (2020). Psychological distress, anxiety, family violence, suicidality, and wellbeing in New Zealand during the COVID-19 lockdown: A cross-sectional study. PLOS ONE, 15(11), e0241658. https://doi.org/10.1371/journal.pone.0241658

Lane, S., \& Mottram, L. (2020). Reports of image based sexual abuse go up by 200 per cent. ABC AM. https://www.abc.net.au/radio/programs/am/reports-of-image-based-sexual-abuse-go-up-by-200-percent/12314476

Lavrakas, P. (2008). Questionnaire-Related Error. In Encyclopedia of Survey Research Methods (1st ed., pp. 660-663). Sage Publications, Inc. https://doi.org/10.4135/9781412963947

Medhora, S. (2020). eSafety office records $340 \%$ spike in complaints as coronavirus impacts online behaviour. Triple J Hack. https://www.abc.net.au/triplej/programs/hack/complaints-esafety-increase341-percent-because-coronavirus/12174654

Pacheco, E., \& Melhuish, N. (2018). New Zealand Teens and Digital Harm: Statistical Insights into Experiences, Impact and Response. SSRN Electronic Journal, 1-50. https://doi.org/10.2139/ssrn.3188608

Poulton, R., Gluckman, P., Menzies, R., Bardsley, A., Mcintosh, T., \& Faleafa, M. (2020). Protecting and promoting mental wellbeing: Beyond COVID-19 (Issue June). https://informedfutures.org/wpcontent/uploads/Protecting-and-Promoting-Mental-Wellbeing.pdf

Sibley, C. G., Greaves, L. M., Satherley, N., Wilson, M. S., Overall, N. C., Lee, C. H. J., Milojev, P., Bulbulia, J., Osborne, D., Milfont, T. L., Houkamau, C. A., Duck, I. M., Vickers-Jones, R., \& Barlow, F. K. (2020). Effects of the COVID-19 pandemic and nationwide lockdown on trust, attitudes toward government, and well-being. American Psychologist, 75(5), 618-630. https://doi.org/10.1037/amp0000662

SWGfL. (2020). Revenge Porn Helpline: The Busiest Year on Record! SWGfL Magazine. https://swgfl.org.uk/magazine/revenge-porn-helpline-the-busiest-year-yet/

Factsheet: The impact of the nationwide COVID-19 lockdown on adult New Zealanders' experiences of unwanted digital communications

Wellington, New Zealand, November 2020

research@netsafe.org.nz

Retrieved from: http://www.netsafe.org.nz/covid19

ISBN: 978-0-473-55084-4

ATTRIBUTION-NONCOMMERCIAL-SHAREALIKE 